\title{
SEJODR
}

\section{Effects of fixed labial and lingual orthodontic appliances on speech sound production: A comparative in vivo study}

\author{
Danish Intesaab, Ahmed*; Ajit, Kalia*; Salil, Nene*; Juhi Joshi*; Girija, Adsure* \\ * M.A.Rangoonwala College Of Dental Sciences And Research Centre, Pune, India
}

\begin{abstract}
Introduction: The eventual esthetic solution for patients who do not want visible orthodontic appliance is the lingual orthodontic appliance. The result produced by the lingual orthodontic appliance is parallel to those produced by the labial orthodontic appliance. However, there is an articulation problem due to the position of the lingual brackets as there is a modification of the lingual surface of the teeth. Speech problems with each appliance are studied individually and extensively, but the comparison of both appliances regarding speech is very scanty. Aim: The aim of this study is to evaluate the effect of fixed labial and lingual orthodontic appliance on speech sound production at a different time interval.

Materials and methods: A total number of 30 patients were included in this study, 15 patients were bonded with the fixed labial appliance (Group 1) and 15 patients were bonded with the fixed self-ligating lingual appliance (Group 2). Based on four types of errors (E1, E2, E3, E4), a total of nine groups of sounds (S1, S2, S3, S4, S5, S6, S7, S8, S9) were evaluated for each audiovisual sample at four different time intervals (T1, T2, T3, T4) by two different speech therapist individually in each group.

Results: A high degree of agreement was found between the two observers in both groups regarding the type of sound effected and the type of error during sound production. The total number of patients with effected speech is more in the lingual group compared to the labial group on the same day of bonding until six months in treatment.

Conclusion: The results of the present study demonstrated the following, the total number of patients with lingual appliance had more errors in speech compared to the labial appliance at the beginning of the treatment. Patients with lingual appliance required more time for adaptation concerning speech. A similar group of sounds was effected in both types of an appliance with a similar type of error. Patients with labial appliance showed more comfort and easier adaptation with the appliance. The anatomical location of the appliance plays an important role in speech alteration and adaptation. These findings should be considered before selecting an appliance for a particular patient.
\end{abstract}

Ahmed DI., Kalia A., Nene S., Joshi J., Adsure G. Effects of fixed labial and lingual orthodontic appliances on speech sound production: A comparative in vivo study. South Eur J Orthod Dentofac Res. 2019;6(2):27-34.

Submitted: September 7, 2019; Revised: October 7, 2019; Published: October 24, 2019

\section{INTRODUCTION}

A complex psycho-physiological process for putting thoughts into words and organizing these words into a sequence with grammatical context is called speech. The physiological media

Corresponding Author:

Dansib Intesaab Abmed

Department Of Orthodontics and Dentofacial Orthopaedics,

M.A.Rangoonwala College of Dental Sciences \& Research Centre,

Pune-1, India

e-mail:intesaab_001@yahoo.com of speech are respiratory, phonatory and articulation. The teeth, in combination with the lips and tongue, play an important role in the articulation of consonants by airflow obstruction and modifications. Therefore tooth position may play a role in articulatory speech disorders. ${ }^{1}$ More and more professional adults are seeking orthodontic treatment in this era; the orthodontist needs to recognize and to determine the possible risk factors affecting communication integrity.

It is eminent that adults have an unenthusiastic reaction towards the esthetics of conventional fixed labial orthodontic appliances 
and want to hide them. Recent advances such as plastic and ceramic bracket and esthetics archwires are available in the market, but the definitive solution to the problem mentioned above is the placement of the brackets on the lingual surface of the teeth. ${ }^{2}$

The solution for the esthetic problem due to the labial orthodontic appliance is the development of lingual orthodontic appliances. The final results of the lingual appliance are as good as the labial appliance..$^{3-6}$ Since the lingual surface of the teeth is altered due to the placement of the lingual brackets, which may often cause articulation problems. ${ }^{7-11}$ The other issues reported to the lingual appliance is oral discomfort, difficulty in chewing, and tongue irritation. ${ }^{12-15}$ The issues mentioned above may lead to the social embarrassment that is greater than that originating from visible labial brackets. ${ }^{16}$

Studies regarding the individual comparison of both the appliances concerning the discomfort during the therapy are ample, but comparison among the two are very few. ${ }^{11-15}$ However, the intensity and extent of oral discomfort caused by lingual appliances compared to that caused by labial appliances are not intelligible yet. To date, there is no published study comparing speech performance between labial and lingual fixed orthodontic treatment that employed acoustic analysis and sonography. Additionally, all of these studies comparing levels of discomfort and speech performance between the two treatment modalities have failed to allot patients to groups randomly (i.e., selection bias may have been present in these investigations)..$^{3-15}$ The goal of this study was to compare the effect of sound speech production between the fixed labial and lingual appliance.

\section{MATERIALS AND METHODS}

This study consisted of total 30 patients of Class I bimaxillary protrusion malocclusion, from which 15 were being treated with labial fixed orthodontics appliance and 15 patients were being treated with lingual fixed orthodontics appliance in the Department of Orthodontics and Dentofacial Orthopaedics. (M.A Rangoonwala dental college and research center, Pune, India).

This research was approved by ethical committee of University (Maharashtra university of health and science, Nasik, India) and Faculty (M.A Rangoonwala dental college and research center, Pune, India).

Group 1 - labial fixed orthodontic appliance bracket system 0.022 slot (American orthodontics) Master/mini series.

Group 2 - lingual fixed orthodontics appliances self ligating bracket system 0.018 slot (Classic orthodontics).

\section{Inclusion criteria}

1. Class I bimaxillary protrusion malocclusion patients who were undergoing fixed labial orthodontic appliance therapy.

2. Class I bimaxillary protrusion malocclusion patients who were undergoing fixed lingual orthodontic appliance therapy.

3. Patients selected were studying or had completed education from a school where the medium of educations is english. (All the subjects were screened and had no mother tongue influence on english language while reading).

\section{Exclusion criteria}

1. Overt dysmorphology such as cleft lip and/or palate.

2. Neurological disorders.

3. Tongue thrust habits.

4. Hearing deficits. (Subjective analysis- patient could follow conversation over 2-5 feet distance without a problem).

5. Prior orthodontic treatment.

6. History of speech or hearing therapy.

\section{Method of data collection}

1. The microphone was mounted on the DSLR camera, then camera was mounted on the tripod. The patient was asked to sit on a chair against a white background 4 feet away from the camera which was on auto focus. The recording was taken in a sound proof room. (Figure 1)

2. A printed poster with pictures and words to be evaluated in bold font was mounted on a stand at a distance of one and half feet from the patient, the mounted poster helped the patient in maintaining an upright natural head position and a parallel Frankfort horizontal plane. (Figure 1, 2)

3. The patient was instructed to read out the poster, and a video with sound was taken (T1) (Figure 3)

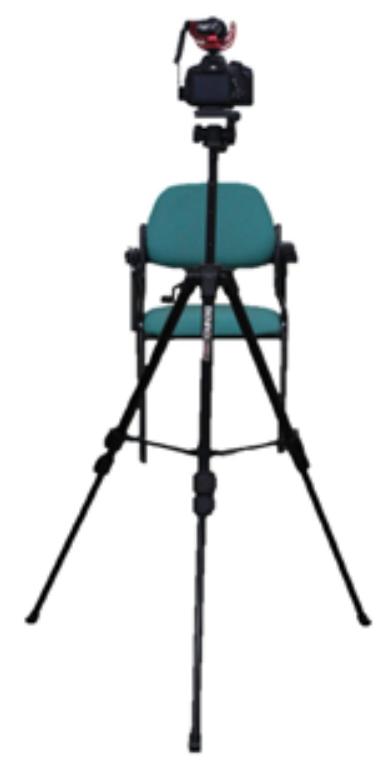

Figure 1. DSLR camera with recording microphone mounted on the tripod against the white background. 


\section{3}

The little boy put the big ball on the table. It rolled fast, seven times. A cat, who was sitting on the sofa, was looking.

Suddenly, she jumped up. Slowly, very slowly, she gave the ball a kiek. The ball slid down on the red and green chair.

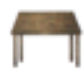

The boy was sad. He ran to his sister, to tell her the story. "Look, Renu. The cat took the gift chacha gave me. The cat is very happy, But I am so sad."

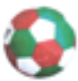

Figure 2. Printed posters with pictures and words.

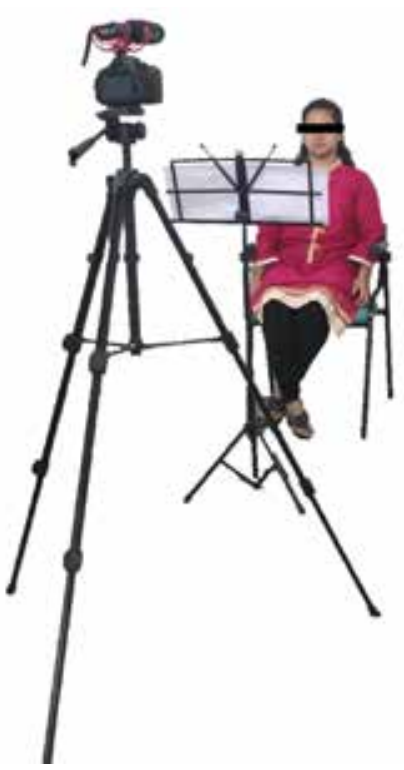

Figure 3. Patient reading the given paper with words and DSLR recording the audio video clip on auto focus.

4. Depending upon the choice of appliance decided for the patient, the appliance was bonded on both the dental arch using the $37 \%$ orthophosphoric acid, bonding agent and adhesive. The method of bonding was direct for both appliances. Then a $0.012 \mathrm{NiTi}$ wire was placed in the both dental arch at the same appointment. (Figure 4a, 4b, 5).

5. Individual ligation was done for the labial appliance with ligature wire. As the lingual appliance was self ligating no ligature wire was used.

6. With the exact same setup again the video audio recording was taken with same poster (T2).

7. After three months $0.014 \mathrm{NiTi}$ wire was placed in both dental arches with the same materials and technique. Again a recording with the same setup was taken (T3).
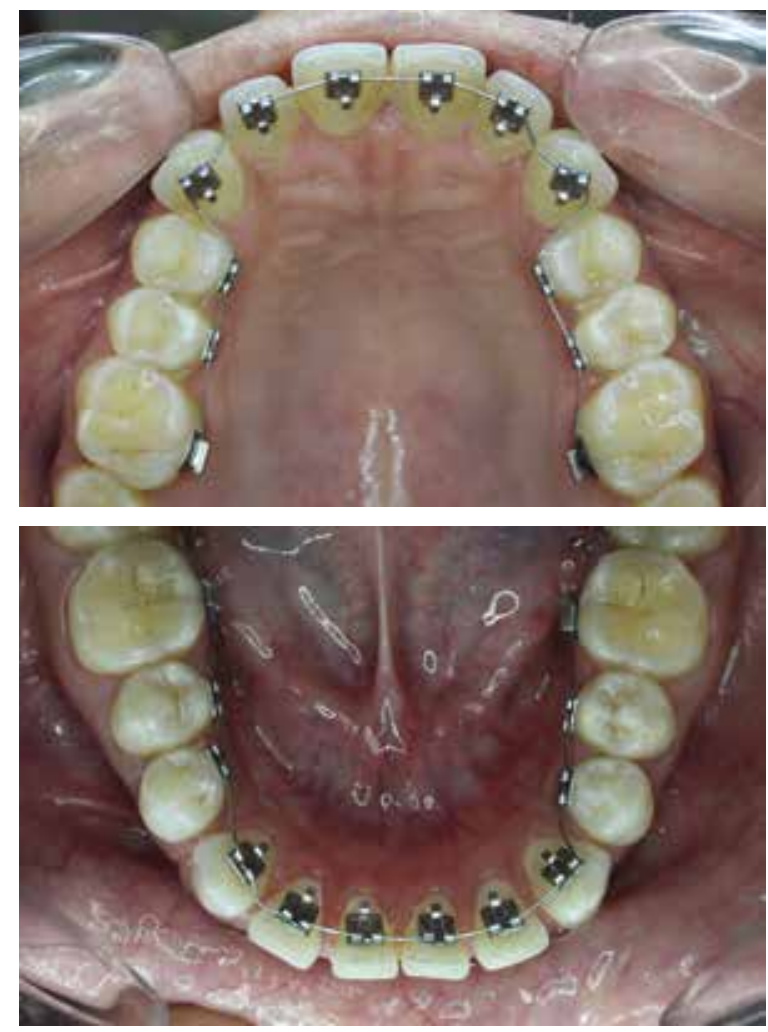

Figure 4a. Lingual appliance bonded on the teeth.

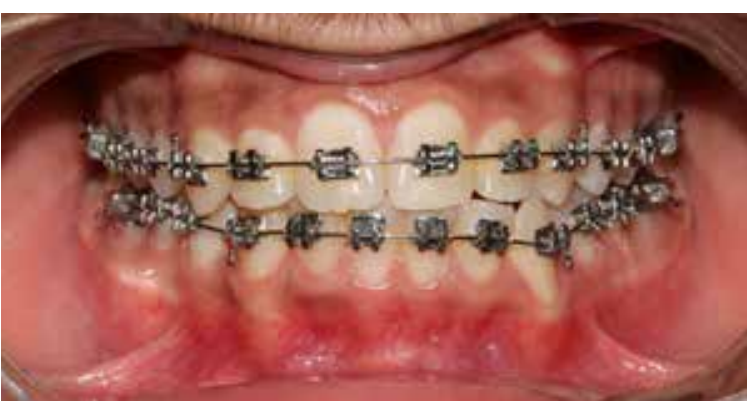

Figure 4b. Labial appliance bonded on the teeth.

8. After 6 months into orthodontic treatment patient was recalled and $0.016 \mathrm{NiTi}$ wire was placed in both the dental arches. Recording was again taken at this point (T4).

9. All the recordings in sequence of $\mathrm{T} 1, \mathrm{~T} 2, \mathrm{~T} 3, \mathrm{~T} 4$ were stored in a folder with the specific patient serial number on it. (Figure 6)

10. In every recording the eyes of the subjects were hidden digitally with a black strip, to hide the identity of the patient.

11. Individually the speech therapist examined each of the recording carefully using windows media player (Figure 7), and evaluated each of them on the chart prepared for that particular patient with the serial number matching the folder. Both the speech therapist were not aware of the age, sex, or the type of appliance used for that particular patient. 


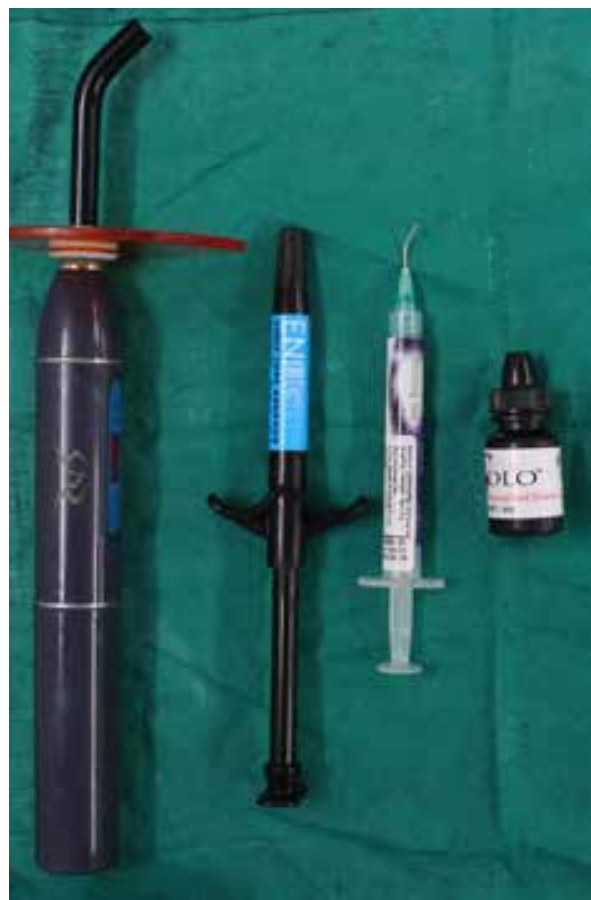

Figure 5. 37\% orthophosphoric acid (etching gel), Bonding agent (Solo universal bonding agent), light cured adhesive (Enlight), LED curing light.

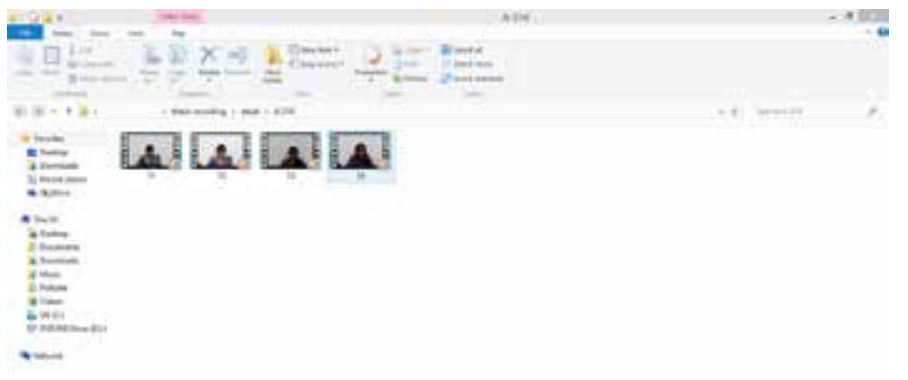

Figure 6. Folder containing all the recordings (T1,T2,T3,T4) with specific serial number.

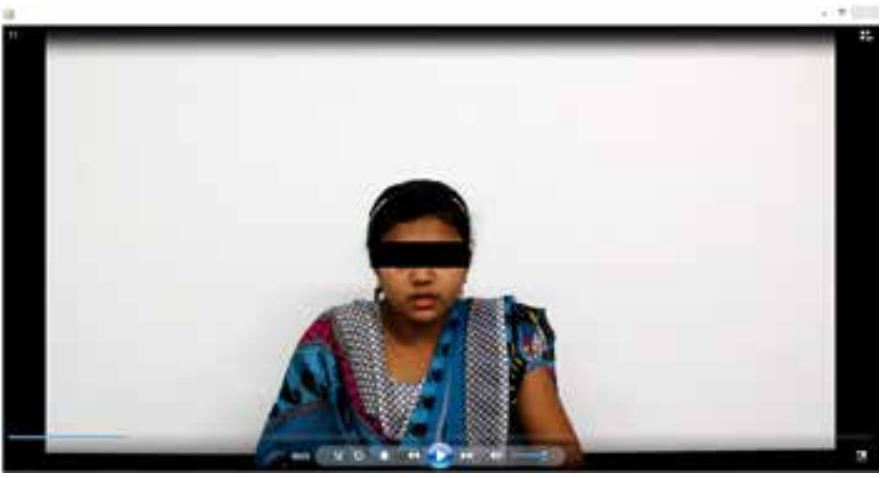

Figure 7. Recording played on the windows media player with eyes covered.
12. Both speech therapist did the analysis at different times, and were unaware of each other's evaluations.

\section{Sample evaluation}

Subjective analysis will be done by two speech therapist, to check for changes in the sound speech sound production (articulation) at different time interval during the orthodontic treatment (same for both groups).

1. A chart is prepared by analyzing the sound in the reading passage into p, b (bilabial, plosives, S1), t, d (alveolar, plosives, S2), k,g (velar, plosives, S3), ch, j (alvelopalatal, affricates, S4), s, z (alveolar, fricatives, S5), 1 (lateral, liquid, S6), r (trill, rolled, S7), sh (alvelopalatal, fricatives, S8), f, v (labiodental, fricatives, S9).

2. On this chart only a serial number is mentioned for each patient (age, sex and group of to which the patient belongs is not reveled to both speech therapist)

3. Each group of articulation is evaluated at each recording (T1, T2, T3, T4). The articulation defect in speech sound production is evaluated based up the distortion, substitution, omission, addition. Distortion is again divided into mild, moderate, severe.

4. For distortion which is mild (D1), distortion which moderate (D2), distortion which is severe (D3), substitution with (S), addition (A) and omission with $(\mathrm{O})$ is written in the chart for each group of articulation for each time of recording which is $\mathrm{T} 1, \mathrm{~T} 2, \mathrm{~T} 3, \mathrm{~T} 4$ respectively.

\section{Statistical analysis}

The following comparisons were done with the help of different statistical tests.

1. To compare inter- observer agreement between the speech therapist, Cohen Kappa Value and P-value by Chi-Square test was used ( $\mathrm{P}$-value $<0.001$ was considered to be highly statistically significant).

2. Inter-group distribution of type of sound affected were compared at different time intervals using $\mathrm{P}$-values by ChiSquare test ( $\mathrm{P}$-value less than 0.05 was considered to be statistically significant) was used.

3. Inter-group distribution of type of error were compared at different time intervals using $\mathrm{P}$-values by Chi-Square test (P-value less than 0.05 was considered to be statistically significant) was used.

4. For overall audio analysis at different time intervals, (intergroup) $\mathrm{P}$-values by Chi-Square test. $\mathrm{P}$-values (intra-group) by Wilcoxon's signed rank test was used (P-value less than 0.05 was considered to be statistically significant). 
The data on categorical variables is shown as $\mathrm{n}$ (\% of cases). The inter-group statistical significance of difference of categorical variables was tested using Chi-Square test or Fisher's exact probability test. The statistical agreement between two observers in identifying the type of sound affected and the type of error committed was assessed using Cohen-Kappa technique. The entire data was entered in MS Excel before its statistical analysis. All the results are shown in tabular as well as graphical format to visualize the statistically significant difference more clearly.

In the entire study, the p-values less than 0.05 are considered to be statistically significant. All the hypotheses were formulated using two tailed alternatives against each null hypothesis (hypothesis of no difference). The entire data was statistically analyzed using Statistical Package for Social Sciences (SPSS ver. 21.0, IBM Corporation, USA) for MS Windows.

\section{RESULTS}

Table 1. Inter-observer agreement for audio-analysis (Sound type)

\begin{tabular}{lllll}
\hline Sound Type & Group 1 (Labial) $(\mathbf{n}=15)$ & Group 2 (Lingual) $(\mathbf{n}=15)$ \\
\hline & Kappa Value & P-value & Kappa Value & P-value \\
\hline S1 & 0.514 & $0.001^{* * *}$ & 0.594 & $0.001^{* * *}$ \\
S2 & 0.615 & $0.001^{* * *}$ & 0.621 & $0.001^{* * *}$ \\
S5 & 0.715 & $0.001^{* * *}$ & 0.744 & $0.001^{* * *}$ \\
S7 & 0.456 & $0.001^{* * *}$ & 0.446 & $0.001^{* * *}$ \\
S8 & 0.696 & $0.001^{* * *}$ & 0.699 & $0.001^{* * *}$ \\
S9 & 0.465 & $0.001^{* * *}$ & 0.466 & $0.001^{* * *}$ \\
\hline
\end{tabular}

Cohen Kappa Value as a measure of statistical agreement between two observers. P-value by Chi-Square test. ${ }^{* * *}$ P-value $<0.001$ (Highly Significant).

\section{Comment}

Since no errors were found in the sound S3,S4 and S6 they are not mentioned in the table.

Table 2. Inter-observer agreement for audio-analysis (Error type)

\begin{tabular}{lllll}
\hline Error Type & Group 1 (Labial) $(\mathbf{n}=15)$ & Group 2 (Lingual) $(\mathbf{n}=15)$ \\
\hline & Kappa Value & P-value & Kappa Value & P-value \\
\hline E1 (Substitution) & 0.847 & $0.001^{* * *}$ & 0.898 & $0.001^{* * *}$ \\
E2 (MildDistortion) & 0.799 & $0.001^{* * *}$ & 0.714 & $0.001^{* * *}$ \\
E3 (Omission) & 0.610 & $0.001^{* * *}$ & 0.619 & $0.001^{* * *}$ \\
E4 (Addition) & 0.498 & $0.001^{* * *}$ & 0.463 & $0.001^{* * *}$ \\
\hline
\end{tabular}

Cohen Kappa Value as a measure of statistical agreement between two observers.

P-value by Chi-Square test. ${ }^{* * *} \mathrm{P}$-value $<0.001$ (Highly Significant).
Table 3. Inter-group and intra-group comparison of overall audio analysis

\begin{tabular}{lllllll}
\hline & $\begin{array}{l}\text { Audio Analysis } \\
\text { Status }\end{array}$ & $\begin{array}{l}\text { Group 1 (Labial) } \\
(\mathbf{n}=15)\end{array}$ & $\begin{array}{l}\text { Group 2 (Lingual) } \\
(\mathbf{n}=15)\end{array}$ & $\begin{array}{l}\text { P-value } \\
\text { (Inter-Group) }\end{array}$ \\
\hline Follow-up & & $\mathrm{n}$ & $\%$ & $\mathrm{n}$ & $\%$ & \\
\hline T1 & Normal & 15 & 100.0 & 15 & 100.0 & $0.999^{\mathrm{NS}}$ \\
& Abnormal & 0 & 0.0 & 0 & 0.0 & \\
\hline T2 & Normal & 11 & 73.3 & 5 & 33.3 & $0.028^{*}$ \\
& Abnormal & 4 & 26.7 & 10 & 66.7 & \\
\hline T3 & Normal & 12 & 80.0 & 6 & 40.0 & $0.025^{*}$ \\
& Abnormal & 3 & 20.0 & 9 & 60.0 & \\
\hline T4 & Normal & 14 & 93.3 & 9 & 60.0 & $0.031^{*}$ \\
& Abnormal & 1 & 6.7 & 6 & 40.0 & \\
\hline P-value & T1 v T2 & $0.100 \mathrm{NS}$ & & $0.001^{* * *}$ & & \\
(Intra- & T1 v T3 & $0.224 \mathrm{NS}$ & & $0.001^{* * *}$ & & \\
Group) & T1 v T4 & $0.999 \mathrm{NS}$ & & $0.017^{*}$ & & \\
\hline
\end{tabular}

P-values (inter-group) by Chi-Square test. P-values (intra-group) by Wilcoxon's signed ank test. P-value less than 0.05 is considered to be statistically significant. ${ }^{*} \mathrm{P}$-value $<0.05,{ }^{* * *} \mathrm{P}$-value $<0.001$, NS-P-value $>0.05$ (Non-Significant).

Table 4. Inter-group distribution of type of sound affected

\begin{tabular}{|c|c|c|c|c|c|c|}
\hline \multirow[b]{2}{*}{ Follow-up } & \multirow{2}{*}{ Sound Affected } & \multicolumn{2}{|c|}{$\begin{array}{l}\text { Group } 1 \text { (Labial) } \\
(n=15)\end{array}$} & \multicolumn{2}{|c|}{$\begin{array}{l}\text { Group } 2 \text { (Lingual) } \\
(n=15)\end{array}$} & \multirow[t]{2}{*}{ P-value } \\
\hline & & $\mathrm{n}$ & $\%$ & $\mathrm{n}$ & $\%$ & \\
\hline \multirow[t]{2}{*}{$\mathrm{T} 1$} & Normal & 15 & 100.0 & 15 & 100.0 & $0.999^{\mathrm{NS}}$ \\
\hline & Abnormal & 0 & 0.0 & 0 & 0.0 & \\
\hline \multirow[t]{6}{*}{$\mathrm{T} 2$} & S2 & 4 & 26.7 & 9 & 60.0 & $0.065^{\mathrm{NS}}$ \\
\hline & S5 & 3 & 20.0 & 5 & 33.3 & $0.409^{\mathrm{NS}}$ \\
\hline & S8 & 3 & 20.0 & 3 & 20.0 & $0.999^{\mathrm{NS}}$ \\
\hline & S9 & 1 & 6.7 & 3 & 20.0 & $0.283^{\mathrm{NS}}$ \\
\hline & S7 & 1 & 6.7 & 1 & 6.7 & $0.999^{\mathrm{NS}}$ \\
\hline & S1 & 1 & 6.7 & 0 & 0.0 & $0.999^{\mathrm{NS}}$ \\
\hline \multirow[t]{6}{*}{ T3 } & S2 & 3 & 20.0 & 9 & 60.0 & $0.060^{\mathrm{NS}}$ \\
\hline & S5 & 0 & 0.0 & 2 & 13.3 & $0.483^{\mathrm{NS}}$ \\
\hline & S8 & 0 & 0.0 & 1 & 6.7 & $0.999^{\mathrm{NS}}$ \\
\hline & S9 & 0 & 0.0 & 0 & 0.0 & $0.999^{\mathrm{NS}}$ \\
\hline & S7 & 0 & 0.0 & 0 & 0.0 & $0.999^{\mathrm{NS}}$ \\
\hline & S1 & 0 & 0.0 & 1 & 6.7 & $0.999^{\mathrm{NS}}$ \\
\hline \multirow[t]{6}{*}{ T4 } & S2 & 1 & 6.7 & 4 & 26.7 & $0.330^{\mathrm{NS}}$ \\
\hline & S5 & 0 & 0.0 & 4 & 26.7 & $0.100^{\mathrm{NS}}$ \\
\hline & S8 & 0 & 0.0 & 1 & 6.7 & $0.999^{\mathrm{NS}}$ \\
\hline & S9 & 0 & 0.0 & 2 & 13.3 & $0.483^{\mathrm{NS}}$ \\
\hline & S7 & 0 & 0.0 & 1 & 6.7 & $0.999^{\mathrm{NS}}$ \\
\hline & S1 & 0 & 0.0 & 1 & 6.7 & $0.999^{\mathrm{NS}}$ \\
\hline
\end{tabular}

P-values (inter-group) by Chi-Square test. P-value less than 0.05 is considered to be statistically significant. ${ }^{*}$ P-value $<0.05,{ }^{* * *} \mathrm{P}$-value $<0.001$, NS-P-value $>0.05$ (Non-Significant). 
Table 5. Inter-group distribution of type of error

\begin{tabular}{lllllll}
\hline & Sound Affected & $\begin{array}{l}\text { Group 1 (Labial) } \\
(\mathbf{n = 1 5})\end{array}$ & \multicolumn{2}{l}{$\begin{array}{l}\text { Group 2 (Lingual) } \\
(\mathbf{n}=15)\end{array}$} & P-value \\
\hline Follow-up & & $\mathrm{n}$ & $\%$ & $\mathrm{n}$ & $\%$ & \\
\hline T1 & Normal & 15 & 100.0 & 15 & 100.0 & $0.999^{\mathrm{NS}}$ \\
& Abnormal & 0 & 0.0 & 0 & 0.0 & \\
\hline T2 & E1 (Substitution) & 4 & 26.7 & 10 & 66.7 & $0.066^{\mathrm{NS}}$ \\
& E2 (Mild Distortion) & 1 & 6.7 & 4 & 26.7 & $0.330^{\mathrm{NS}}$ \\
& E3 (Omission) & 2 & 13.3 & 3 & 20.0 & $0.999^{\mathrm{NS}}$ \\
& E4 (Addition) & 1 & 6.7 & 1 & 6.7 & $0.999^{\mathrm{NS}}$ \\
\hline T3 & E1 (Substitution) & 3 & 20.0 & 9 & 60.0 & $0.060^{\mathrm{NS}}$ \\
& E2 (Mild Distortion) & 0 & 0.0 & 2 & 13.3 & $0.483^{\mathrm{NS}}$ \\
& E3 (Omission) & 0 & 0.0 & 2 & 13.3 & $0.483^{\mathrm{NS}}$ \\
& E4 (Addition) & 0 & 0.0 & 1 & 6.7 & $0.999^{\mathrm{NS}}$ \\
\hline T4 & E1 (Substitution) & 1 & 6.7 & 6 & 40.0 & $0.080^{\mathrm{NS}}$ \\
& E2 (Mild Distortion) & 1 & 6.7 & 3 & 20.0 & $0.283^{\mathrm{NS}}$ \\
& E3 (Omission) & 0 & 0.0 & 2 & 13.3 & $0.483^{\mathrm{NS}}$ \\
& E4 (Addition) & 0 & 0.0 & 0 & 0.0 & $0.999^{\mathrm{NS}}$ \\
\hline
\end{tabular}

$\mathrm{P}$-values (inter-group) by Chi-Square test. P-value less than 0.05 is considered to be statistically significant. ${ }^{*} \mathrm{P}$-value $<0.05,{ }^{* * *} \mathrm{P}$-value $<0.001, \mathrm{NS}$-P-value $>0.05$ (Non-Significant).

\section{DISCUSSION}

Speech sound production is a complex process that involves precise planning, coordination, and movement of different articulators (such as the jaw, lips, teeth, tongue, palate, cheeks, and "voice box"). Speech is also our verbal way of communicating, and it has a phonetic level as well as a phonological level. The phonetic level is also known as 'articulation' and is concerned with the act of producing consonants and vowel sounds, while the phonological level is concerned with how the brain organizes the speech sounds into patterns.

Correct articulation produces clear speech. Another name for clear speech is intelligibility. Errors in speech sound production are known as articulation errors. Articulation errors are common in children when they first learn to speak. An example of this is a toddler who says "wabbit" for "rabbit." Most children eventually outgrow such speech errors, which are a normal part of learning to produce new sounds. (Note: Regional dialects, such as a "Boston / $\mathrm{r} /$ ", are not articulation errors.)

This was a comparative study in which the effect of fixed labial and lingual orthodontic appliance on speech and sound production at different time intervals was recorded.

Evidence from Frowine and Moser with a small case series showed that irrespective of malocclusion, patients resented with satisfactory speech. ${ }^{16}$ Rathbone felt that poor speech and malocclusion were related, but there was no direct relationship between the severity of malocclusion and the severity of speech defects in a small sample. ${ }^{17}$
Hopkin and McEwen found that speech defects were just as likely to occur in subjects with malocclusion. ${ }^{18}$

Teeth are articulator organs for formation of sound. The lack of teeth can cause abnormal sound. ${ }^{19}$ Relation of maxilla and mandible, tongue and oral cavity have important role for formation of the sounds. Relation of maxilla and mandible varies in every patient. Class II patients have difficulties on "p", "b", "m" and "s" sounds. Class III patient have difficulties on "s", "z", "f " and "v" sounds. The way of speaking of patient should be carefully examined, the reasons should be identified which could cause problems in the sound formation. ${ }^{20}$ This shows that different malocclusion without any appliance have an effect on different sounds during speech. So only patients with class I malocclusion were taken in this study so that the malocclusion has negligible effect on sound production and maximum effect of the appliance can be studied. ${ }^{21,22}$

It was not enough to just find out errors at different time intervals during treatment by different appliance, if the errors were present for a longer duration during the orthodontic treatment then the patient may socially lose confidence due to improper speech. This may also require a speech therapist and orthodontist working together to resolve this problem. So for the better understanding of the sounds by the speech therapist for speech therapy if required, they were divided into nine groups according to the international phonetic alphabets chart, this division were also done in previous studies for analysis of speech. ${ }^{17,23}$

Fillion ${ }^{12}$ studied the effects of lingual appliance presence on patients in his practice at least one month following the fit of an appliance and found that around one third of patients reported speech problems as the issue that bothered them the most, indeed, around $20 \%$ of the study group still had speech problems a month after having the appliance fitted. Moreover, another study found that $23 \%$ of patients still had significant speech problems three months following the start of lingual appliance treatment. ${ }^{2}$ There are many other studies which reports errors in speech, in some patients at 6 months in to the treatment. ${ }^{2,14-16}$ So a long term follow up was designed for this study.

According to this study errors in speech in the Labial group is only seen in hand full of patients at start of the treatment which progress to almost none (seen only in one patient at T4) as the treatment progresses till $\mathrm{T} 4$. The reason for errors in the initial months of the treatment could be Pain and tension following initial arch wire engagement may change in oral habits and cause speech disturbances. ${ }^{23,24}$ The small number of patients effect with speech after immediate bonding of the appliance and quick adaptation to the appliance within few month is in agreement with other studies also. ${ }^{25-27}$

In the Lingual group the errors in speech was reported in more than half of the patients immediately after the bonding of the appliance $(66.7 \%$ at T2) which significantly reduced at each time interval and later remained in $40 \%$ of the patients at 6 months interval. This study showed a marked number of people effected 
immediately after bonding the lingual appliance and there was slow adaptation of speech as the treatment progresses, this finding is similar to that of other studies. ${ }^{2,23,28,29}$ The probable reason behind this could be; speech is a finely coordinated and subconscious skill requiring very specific positioning of the tongue. Any disturbance to this process can change the sound of speech, so the presence of brackets connected by an arch wire on the lingual surfaces of the teeth cause speech problems because of the physical thickness of the materials used. According to a study by Thomas Stamm et al ${ }^{30}$, the customized lingual bracket system has an increased bracket bulk due the addition of composite at the base of the bracket and larger appliance design, which may correlate to the speech errors due to delayed tongue adaptation when compared to prefabricated lingual appliance similar to the one used in this study. The increased bulk of the appliance prevents the tongue to create a seal with lingual surfaces of the teeth, increased pressure exerted by the tongue may help to create a seal, but this in turn, may cause soft tissue discomfort. The change in tongue activity during connected speech means that speech either needs to be slower, or errors in speech start to appear. This seems to be the case when patients are nervous about talking, and may speak more quickly, rather than slowing their speech down. This can lead to a circle of speech problems in some patients: attempts to adapt, producing discomfort and then discomfort leading to further speech difficulty.

Some patients showed faster adaptation to appliance in both groups this can be due to effusive nature of the patient. People who speak more, may be more likely to have developed strategies to overcome barriers to the speech, whereas people who are very quiet may have more difficulty adapting. There is however, very little quality evidence to show that this is the case. ${ }^{31}$

As in earlier studies, ${ }^{22,31,33}$ the phonemic errors seen, $/ \mathrm{s} /$ and $/ \mathrm{t} /$, were most commonly affected by the presence of labial fixed appliances. Moreover, $/ \mathrm{s} / \mathrm{and} / \mathrm{t} /$ findings were the most frequent sound error across languages as well. ${ }^{34}$ These findings in the studies mentioned above are similar to those found in this study. Subtelny and coworkers ${ }^{32}$ noted, the articulatory error of $/ \mathrm{s} / \mathrm{can}$ be a result of excessive fronting of the tongue.

The most common type of error found at all time intervals was substitution (S), followed by mild distortion (D1), though it was higher in lingual group compared to labial group.

Robert D. later ${ }^{31}$ suggested the following factor to overcome the speech difficult with fixed orthodontic appliance. Discussion with the patient prior to treatment should include information about speech problems being a possibility and that, while most patients cope very well, some patients are more susceptible than others. Appliance selection should also be considered, Advice regarding the period of time taken to adapt to an appliance should also be given. Patients should be advised to speak more slowly while adapting. This can be done without others noticing if the speed of speech is changed a small amount. Keeping the appliance comfortable and instructing how to do this using wax and silicone based products, particularly if sliding mechanics are being used. Comfort can also be helped by either cutting ends flush using a diamond bur or with a fast hand piece, or turning the ends in labially, using a triple beak plier. Compensatory articulation can be achieved by placing the tongue slightly higher during speech (away from the level of the appliance) or using slightly different language; 'Holland' for example, is far easier to say with a lingual appliance in place, than 'The Netherlands'. ${ }^{32-35}$ In 1960, Fairbanks ${ }^{36}$ included a passage in his 'Voice and articulation drillbook', called 'The Rainbow Passage'. This English language passage has become used to test a person's ability to use connected speech. It is also possible for patients to record their speech and listen to it and practicing reading aloud can help patients adapt to the presence of lingual appliances. ${ }^{10}$ If a patient has ongoing difficulties with speech, referral to a speech therapist could be considered, but this is unlikely to be necessary with the design of appliances now in common use.

This study shows that the lingual technique is indeed more demanding on the patient's part when compared to its labial counterpart with respect to speech performance. It thus becomes the responsibility of the orthodontist to inform the patient about the initial difficulties and be sympathetic and supportive during the adaptive phase. All change is hard at first, messy in the middle and gorgeous at the end.

This study was conducted with standardized malocclusion with a long term follow up. Evaluation were done with multiple observers by taking a large groups of sounds under consideration with all the type of error possible. Similar type of appliance were used in all the patient in each group. Still there are many limitations in the study, first of all this is in an subjective analysis not an objective analysis such as spectrographic analysis. The age, sex and the cephalometric values of the patients are not taken into consideration. A larger subject size for both group can also add to the impact of the study.

\section{CONCLUSION}

The results of the present study demonstrated the following, the total number of patients with lingual appliance had more error in speech compared to labial appliance at the beginning of the treatment. Patients with lingual appliance required more time for adaptation with regard to speech. Similar group of sounds were effected in both type of appliance with similar type of error. Patients with labial appliance showed more comfort and easier adaptation with the appliance. It is clear that the anatomical location of the appliance plays an important role in speech alteration and adaptation. These findings should be considered before selecting an appliance for a particular patient.

\section{CONFLICT OF INTEREST}

The authors declares that there is no conflict of interest regarding the publication of this paper. 


\section{REFERENCES}

1. Van Riper C. Speech correction: Principles and methods. New jersey: Prentice Hall, 1978. https://trove.nla.gov.au/work/3567865

2. Caniklioglu C, Oztürk Y. Patient discomfort: a comparison between lingual and labial fixed appliances. Angle Orthod. 2005;75(1):86-91.

3. Gorman JC. Treatment of adults with lingual orthodontic appliances. Dent Clin North Am. 1988;32(3):589-620.

4. Gorman JC, Smith RJ. Comparison of treatment effects with labial and lingual fixed appliances. Am J Orthod Dentofacial Orthop. 1991;99(3):202-9.

5. Grauer D, Proffit WR. Accuracy in tooth positioning with a fully customized lingual orthodontic appliance. Am J Orthod Dentofacial Orthop. 2011;140(3):433-43.

6. Pauls AH. Therapeutic accuracy of individualized brackets in lingual orthodontics. J Orofac Orthop. 2010;71(5):348-61. (English, German)

7. Marioti J, Subtelny JD, Baker R, Marioti M. The Speech Effect of the Lingual Appliance. Orange, Calif: ORMCO Co;1984. https://ormco.com > download > civ1-1984-01

8. Fujita K. Multilingual-bracket and mushroom arch wire technique. A clinical report. Am J Orthod. 1982;82(2):120-40.

9. Alexander CM, Alexander RG, Sinclair PM. Lingual orthodontics: a status report. Part 6. Patient and practice management. J Clin Orthod. 1983;17(4):240-6.

10. Smith JR, Gorman JC, Kurz C, Dunn RM. Keys to success in lingual therapy. Part 1. J Clin Orthod. 1986;20(4):252-61. Erratum in: J Clin Orthod 1986;20(9):604.

11. Sinclair PM, Cannito MF, Goates LJ, Solomos LF, Alexander CM.Patient responses to lingual appliances. J Clin Orthod. 1986;20(6):396-404.

12. Fillion D. Improving patient comfort with lingual brackets. J Clin Orthod. 1997;31(10):689-94.

13. Artun J. A post treatment evaluation of multibonded lingual appliances in orthodontics.Eur J Orthod. 1987;9(3):204-10.

14. Fritz U, Diedrich P, Wiechmann D. Lingual technique--patients' characteristics, motivation and acceptance. Interpretation of a retrospective survey. J Orofac Orthop. 2002;63(3):227-33. (English, German)

15. Wu A, McGrath C, Wong RW, Wiechmann D, Rabie AB.Comparison of oral impacts experienced by patients treated with labial or customized lingual fixed orthodontic appliances. Am J Orthod Dentofacial Orthop. 2011;139(6):784-90.

16. Frowine VK, Moser H. Relationship of dentition and speech. Journal A.D.A. 1944; 31:1081-90.

17. Benediktsson, E. Variation in Tongue and Jaw Position in "S" Sound Production in Relation to Front Teeth Occlusion. Acta Odontol Scand, 1958;15(4), 275-304.

18. Hopkin GB. Orthodontic aspects of the diagnosis and management of speech defects in children. Proc R Soc Med. 1972;65(4):409-13.

19. Sayar G. Pain and chewing sensitivity during fixed orthodontic treatment in extraction and non-extraction patients. J Istanb Univ Fac Dent. 2017;51(2):23-28.

20. Van Lierde KM, Schepers S, Timmermans L, Verhoye I, Van Cauwenberge P. The impact of mandibular advancement on articulation, resonance and voice characteristics in Flemish speaking adults: a pilot study. Int J Oral Maxillofac Surg. 2006;35(2):137-44.

21. Johnson NC, Sandy JR. Tooth position and speech--is there a relationship? Angle Orthod. 1999;69(4):306-10.

22. Leavy KM, Cisneros GJ, LeBlanc EM. Malocclusion and its relationship to speech sound production: Redefining the effect of malocclusal traits on sound production. Am J Orthod Dentofacial Orthop. 2016;150(1):116-23.

23. Sergl HG, Klages U, Zentner A. Functional and social discomfort during orthodontic treatment--effects on compliance and prediction of patients' adaptation by personality variables. Eur J Orthod. 2000;22(3):307-15.

24. Nanda RS, Kierl MJ. Prediction of cooperation in orthodontic treatment. Am J Orthod Dentofacial Orthop. 1992;102(1):15-21.

25. Van Lierde KM, Luyten A, D'haeseleer E, Van Maele G, Becue L, Fonteyne E, Corthals P, De Pauw G. Articulation and oromyofunctional behavior in children seeking orthodontic treatment. Oral Dis. 2015;21(4):483-92.

26. Khattab TZ, Farah H, Al-Sabbagh R, Hajeer MY, Haj-Hamed Y. Speech performance and oral impairments with lingual and labial orthodontic appliances in the first stage of fixed treatment. Angle Orthod. 2013;83(3):519-26.

27. Paley JS, Cisneros GJ, Nicolay OF, LeBlanc EM. Effects of fixed labial orthodontic appliances on speech sound production. Angle Orthod. 2016;86(3):462-7.

28. Rai KA, Ganeshkar SV, Rozario JE. Parametric and nonparametric assessment of speech changes in labial and lingual orthodontics: A prospectivestudy. APOS Trends in Orthodontics. 2013;3(4):99-109.

29. Papageorgiou SN, Gölz L, Jäger A, Eliades T, Bourauel C. Lingual vs. labial fixed orthodontic appliances: systematic review and meta-analysis of treatment effects. Eur J Oral Sci. 2016;124(2):105-18.

30. Stamm T, Hohoff A, Ehmer U. A subjective comparison of two lingual bracket systems. Eur J Orthod. 2005;27(4):420-6.

31. Slater RD. Speech and discomfort during lingual orthodontic treatment. J Orthod. 2013;40 Suppl 1:S34-7.

32. Subtelny JD, Mestre JC, Subtelny JD. Comparative study of normal and defective articulation of $/ \mathrm{s} /$ as related to malocclusion and deglutition. J Speech Hear Disord. 1964;29:269-85.

33. Vallino LD, Tompson B. Perceptual characteristics of consonant errors associated with malocclusion. J Oral Maxillofac Surg. 1993;51(8):850-6.

34. Sahad M, Nahas A, Scavone H Jr, Jabur LB, Guedes-Pinto E. Vertical interincisal trespass assessment in children with speech disorders. Vertical interincisal trespass assessment in children with speech disorders. Brazilian Oral Research.2008; 22(3), 247-251.

35. Leme MS, De Souza Barbosa T, Gaviao MBD. Relationship among oral habits, orofacial function an oral health-related quality of life in children. Brazilian Oral Research.2013;27(3), 272-278.

36. Fairbanks G. Voice and Articulation Drillbook, 1st Edn. New York: Harper, 1960. 